\title{
The World Journal of Surgery Welcomes Associate Editor-Ronnie T. P. Poon
}

\author{
John G. Hunter
}

Published online: 14 May 2009

(C) Société Internationale de Chirurgie 2009

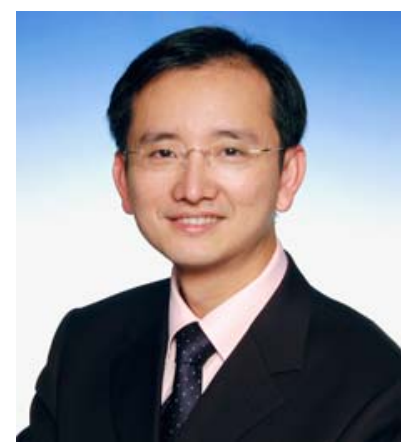

The World Journal of Surgery welcomes Ronnie T. P. Poon, our new Associate Editor, from Hong Kong, China. Prof. Poon attended medical school and served his general surgery residency at the University of Hong Kong, where he obtained a PhD for his work on tumor angiogenesis. Prof. Poon's main clinical and research interest is in hepatobiliary and pancreatic surgery. In particular, he has devoted much of his research effort to the management of liver cancer, ranging from surgical resection or ablation for early cancer to molecular targeted therapy for advanced disease. He is the author of over 240 full articles in international journals and 14 book chapters. He has delivered over 180 lectures in various regional and international conferences on his research work. He has contributed to the establishment of consensus guidelines on management and research on liver cancer by various international organizations. He is the Founding Board Member of the International Liver Cancer Association, and he serves in the Research and Scientific Committees of the International Hepato-Pancreato-Biliary Association.

Prof. Poon has received several awards for his research accomplishments, including the G. B. Ong Traveling Fellowship in 2001, Outstanding Young Researcher Award of the University of Hong Kong in 2003, the International Guest Scholarship of the American College of Surgeons in 2006, Outstanding Researcher Award of the University of Hong Kong 2007, and the James IV Traveling Fellowship for 2007. In addition to his role as Associate Editor of the World Journal of Surgery, he also serves in the editorial board of several surgical, gastroenterology, and oncology journals including Cancer Therapy, World Journal of Gastroenterology, Journal of Gastroenterology and Hepatology, HBP Surgery, Journal of Gastrointestinal Surgery, and Annals of Surgical Oncology. We are thrilled to have Prof. Poon join our international panel of expert associate editors.
J. G. Hunter $(\bowtie)$

Department of Surgery, Oregon Health Sciences University, School of Medicine, 3181 S.W. Sam Jackson Park Road, Portland, OR 97239-3098, USA

e-mail: hunterj@ohsu.edu 